\title{
Spontaneous Bending of Ni-Ti Alloy Plates Caused by Preferential Hydrogen Absorption
}

\author{
K. Horikawa, Y. Kawabata* and H. Kobayashi \\ Department of Mechanical Science and Bioengineering, School of Engineering Science, \\ Osaka University, Toyonaka 560-8531, Japan
}

When the polished Ni-Ti alloy plates were hydrogen charged cathodically, it was newly found that the plates were bent spontaneously as the hydrogen charging time increased. The degree of the spontaneous bending was closely related to the structural change on the surface of the plates. When only one side of the specimen surfaces was polished by an emery paper or buffed, the spontaneous deformation was clearly identified after hydrogen charging. In contrast, when both sides of the specimen surfaces were polished in the same level, such deformation was not observed. Thermal hydrogen desorption analysis showed that the degree of the spontaneous bending was clearly related to the difference of the hydrogen concentration, probably in the thickness direction. It was also found that when hydrogen was released from the specimen by heating, the spontaneous bending was disappeared. Based on the X-ray diffraction analysis of the polished specimen surfaces before and after hydrogen charging, it was revealed that the amount of hydrogen entered into the specimen was promoted by the polishing because of the crystal lattice distortion and the strain-induced martensite transformation. [doi:10.2320/matertrans.MA200801]

(Received February 5, 2008; Accepted June 6, 2008; Published July 24, 2008)

Keywords: nickel-titanium alloy, hydrogen, bending, thermal desorption analysis, X-ray diffraction (XRD)

\section{Introduction}

The Ni-Ti alloys are known to show shape memory and superelastic effects based on the transformation from the cubic (B2) austenite to the monoclinic (B19') martensite. ${ }^{1)}$ By utilizing these functional effects, the $\mathrm{Ni}$-Ti alloy has been widely used for industrial and medical devises. On the other hand, it has been reported that the shape memory properties $^{2-5)}$ and the mechanical properties ${ }^{6-10)}$ of the Ni-Ti alloy were affected by atmospheric hydrogen. It was reported that the martensite temperature slightly decreased as the hydrogen charging time, and the ductility decreased when the hydrogen charged alloy was tested at a slow strain rate. Apart from such effects, the authors have found the unique phenomenon $^{11)}$ that the Ni-Ti alloy plates were spontaneously bent after hydrogen charging cathodically depending on the difference of the polishing on the specimen surface at room temperature as shown in Fig. 1. It is believed that this effect is substantially not related to the shape memory or superelastic properties since the bending is brought about at the constant temperature under the reverse martensite temperature. It is expected that this phenomenon would be applicable for a hydrogen sensor or an actuator. Thus far, the relationship between the hydrogen absorption and the spontaneous deformation behavior has not been understood. The purpose of this paper is to investigate the effect of hydrogen on the spontaneous deformation behavior of the $\mathrm{Ni}$-Ti alloy plate, in connection of the structural change on the specimen surface.

\section{Experimental Procedure}

The Ni-55.2 mass \% Ti alloy ingots of $68 \mathrm{~mm}$ in diameter were hot rolled at $850^{\circ} \mathrm{C}$ to the plates of $4.5 \mathrm{~mm}$ in thickness. Homogenization of the hot rolled sheets was performed at $750^{\circ} \mathrm{C}$ for $0.5 \mathrm{~h}$ and quenched in water. The oxidation layers

*Graduate Student, Osaka University

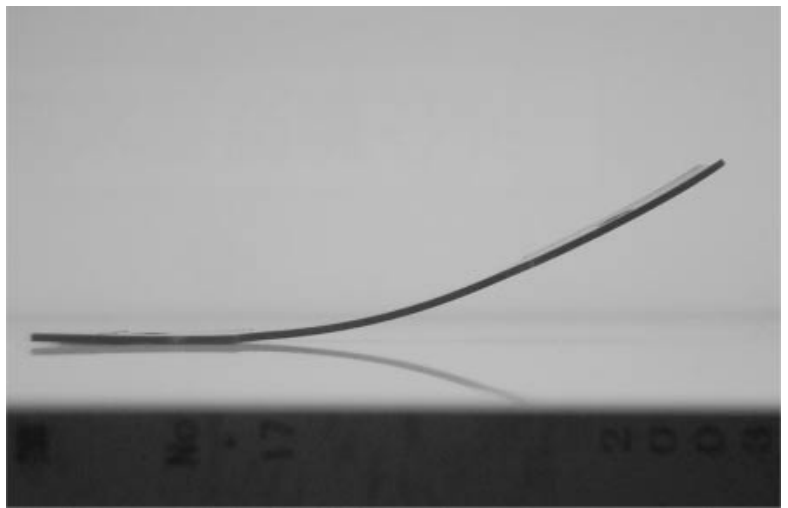

Fig. 1 Spontaneous bending caused by hydrogen charging in a Ni-Ti alloy.

on the surface of the hot rolled sheets were removed by pickling. Finally, the plates of $0.9 \mathrm{~mm}$ in thickness were obtained by cold rolling. For the cold rolled plates, heat treatment was performed at $675^{\circ} \mathrm{C}$ for $1 \mathrm{~h}$ in an argon atmosphere and then cooled to room temperature. The alloy contains 0.05 mass $\%$ of carbon, 0.035 mass $\%$ of oxygen, 0.02 mass $\%$ of iron as impurity elements. Other impurities contents such as copper and chromium were reduced to below 0.003 mass $\%$. The transformation temperature determined with differential scanning calorimetry (DSC) and mechanical properties ${ }^{8)}$ of the alloy was shown in Table 1.

Here, $M_{\mathrm{s}}$ and $M_{\mathrm{f}}$ represents the start and finish temperatures for the martensite transformation during cooling, and $A_{\mathrm{s}}$ and $A_{\mathrm{f}}$ represents the start and finish temperatures for reverse martensite transformation. The following experiments, machining, polishing, hydrogen charging and observation were performed at the constant temperature $25^{\circ} \mathrm{C}$ which corresponded to the temperature lower than $A_{\mathrm{s}}$. Rectangular test specimens with a size of $40 \mathrm{~mm}$ in length, $4 \mathrm{~mm}$ in width, and $1 \mathrm{~mm}$ in thickness were cut from the cold rolled plates. The difference of the polishing condition for the specimens is shown in Table 2. 
Table 1 Mechanical properties and transformation temperatures of the Ni-Ti alloy.

\begin{tabular}{cccccc}
\hline $\begin{array}{c}\text { Critical Stress } \\
(\mathrm{MPa})\end{array}$ & Critical Strain & Tensile Strength & \multicolumn{3}{c}{ Transformation temperature $\left({ }^{\circ} \mathrm{C}\right)$} \\
\cline { 3 - 5 } & $(\%)$ & $(\mathrm{MPa})$ & $A_{\mathrm{f}}$ & $A_{\mathrm{s}}$ & $M_{\mathrm{s}}$ \\
\hline 120 & 3.0 & 1180 & 52.5 & 38.0 & 23.0 \\
\hline
\end{tabular}

Table 2 Polishing condition.

\begin{tabular}{ll}
\hline Specimen A & Unpolished \\
\hline Specimen B & Polished with a \#180 emery paper (One side) \\
\hline Specimen C & Buffed (One side) \\
\hline Specimen D & Buffed (Both sides) \\
\hline
\end{tabular}

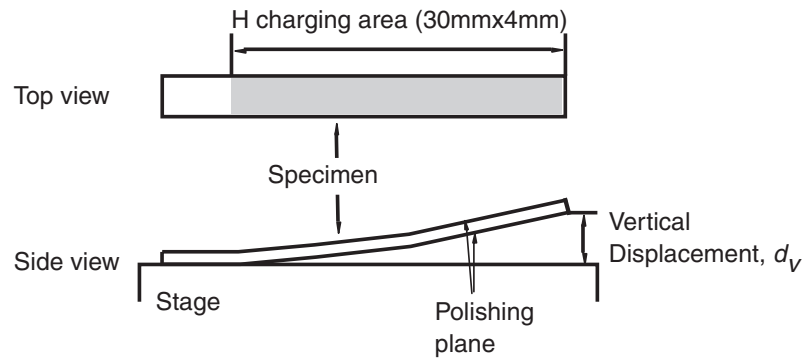

Fig. 2 Measurement of the spontaneous bending.

Specimen A is the as-received specimen without polishing. Specimen B is the specimen that only one side of the specimen surfaces was polished using a \#180 SiC paper. Specimen C and Specimen D are the specimens that one or both sides of the surfaces were buffed with alumina powder (grain size: $0.3 \mu \mathrm{m}$ ) solution, respectively. Surface roughness of the specimens after polishing was measured with a laser microscope. The test specimens were hydrogen charged cathodically in 0.9 mass $\% \mathrm{NaCl}$ electrolyte solution with a current density of $100 \mathrm{Am}^{-2}$ for time ranging from $0 \mathrm{~h}$ to $6 \mathrm{~h}$. The degree of the spontaneous bending by hydrogen charging was measured by the vertical displacement at the free end of the test specimens as shown in Fig. 2. The amount of hydrogen containing in the specimen with and without hydrogen charging was measured by the thermal deposition analysis (TDA) using gas chromatography. The amount of hydrogen gas was measured at 1 min intervals during heating a sample weighed about $1 \mathrm{~g}$. High purity argon carrier gas was passed through a quartz glass tube at a flow rate of $20 \mathrm{~mL} \mathrm{~min}^{-1}$. Hydrogen concentration was detected at $5 \mathrm{~min}$ intervals with a heating rate of $100^{\circ} \mathrm{C} \mathrm{min}^{-1}$ until the temperature reached $900^{\circ} \mathrm{C}$. The specimen surfaces were also characterized by the X-ray diffraction (XRD) method with Co $K_{\alpha}$ radiation.

\section{Results and Discussion}

\subsection{Effect of polishing condition on spontaneous bending}

The relationship between the polishing condition and the vertical displacement after hydrogen charging is shown in Fig. 3. The specimen was not bent when both sides of the specimen surfaces were not polished (Specimen A) or buffed

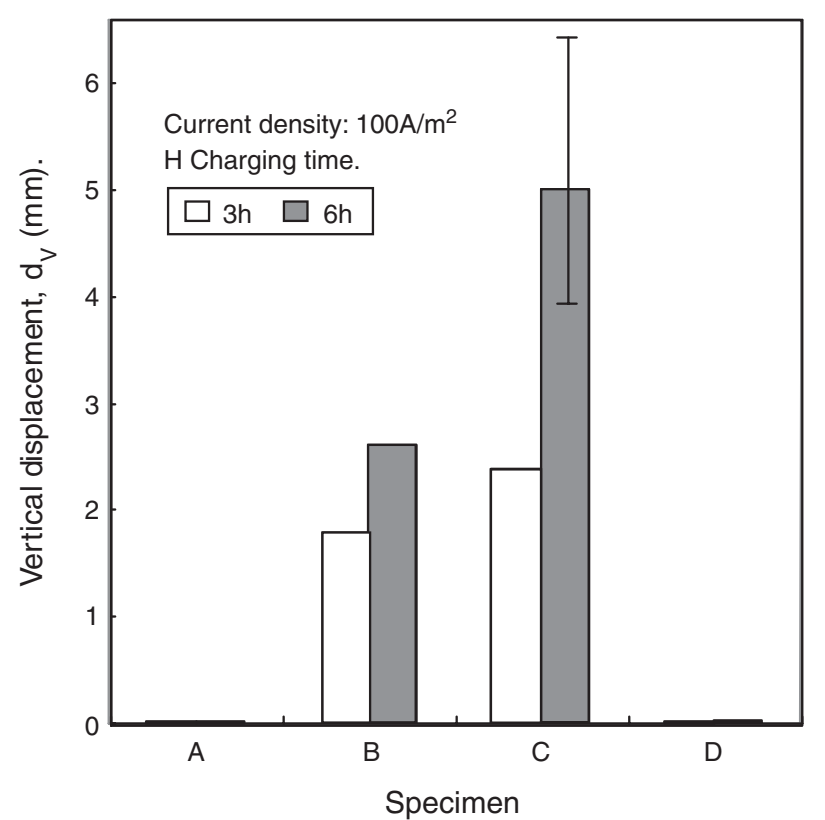

Fig. 3 Vertical displacement after hydrogen charging.

(Specimen D) after hydrogen charging. In contrast, when only one side of the specimen surfaces was polished by the emery paper or buffed (Specimen B and Specimen C), the spontaneous bending was clearly identified after hydrogen charging. For Specimen B and Specimen C, the vertical displacement was both increased when the hydrogen charging time increased. It was found that the spontaneous bending was brought about in the way that the polished surface always lengthened. When it compared the degree of the spontaneous bending by the difference of the way of polishing, the spontaneous bending was more prominent in the case of buffing rather than polishing using emery papers. Thus, it is clear that the polishing condition greatly affects the spontaneous bending after hydrogen charging.

The average surface roughness, $R_{\mathrm{z}}$ of the specimens before polishing was about $16 \mu \mathrm{m}$, that after emery polishing (\#180) was about $11 \mu \mathrm{m}$ and that after buffing was about $3 \mu \mathrm{m}$. Then, surface roughness of both sides of the specimen was controlled by using different emery papers, \#180, \#800, $\# 1200$, and then the spontaneous bending was examined. Figure 4 shows the relationship between the difference of the surface roughness of both sides and the spontaneous bending. If the surface roughness between both sides was changed, the spontaneous bending was brought about even when both sides of the surfaces were polished. This indicates that the degree of the spontaneous bending can be variable by the difference of the surface roughness between both sides.

\subsection{Hydrogen desorption and spontaneous bending}

Figure 5 shows the hydrogen desorption rate as a function of temperature obtained from TDA in the specimens after 


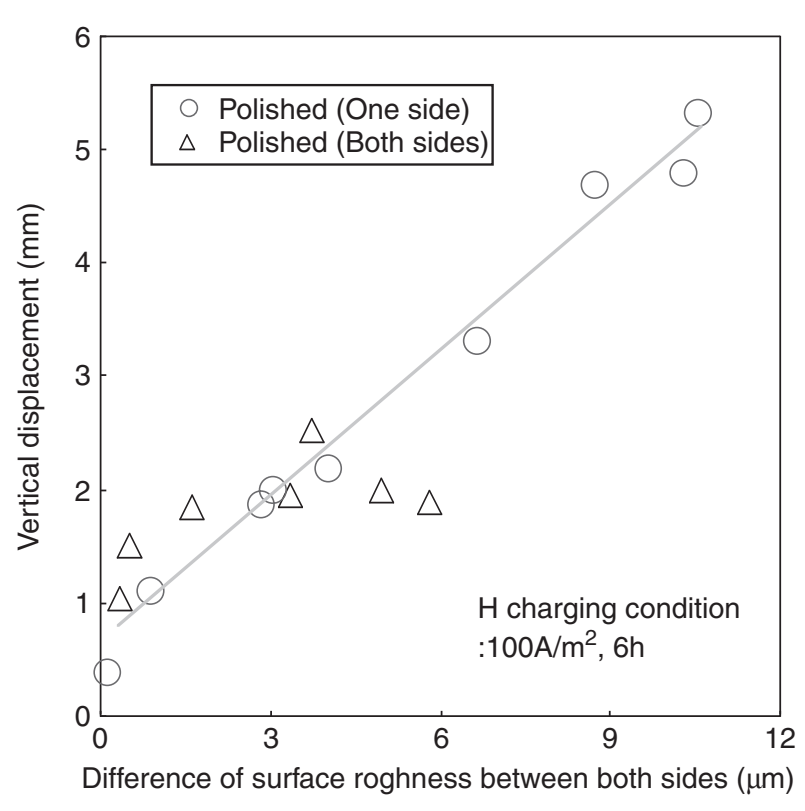

Fig. 4 Vertical displacement vs. difference of the surface roughness between both sides.

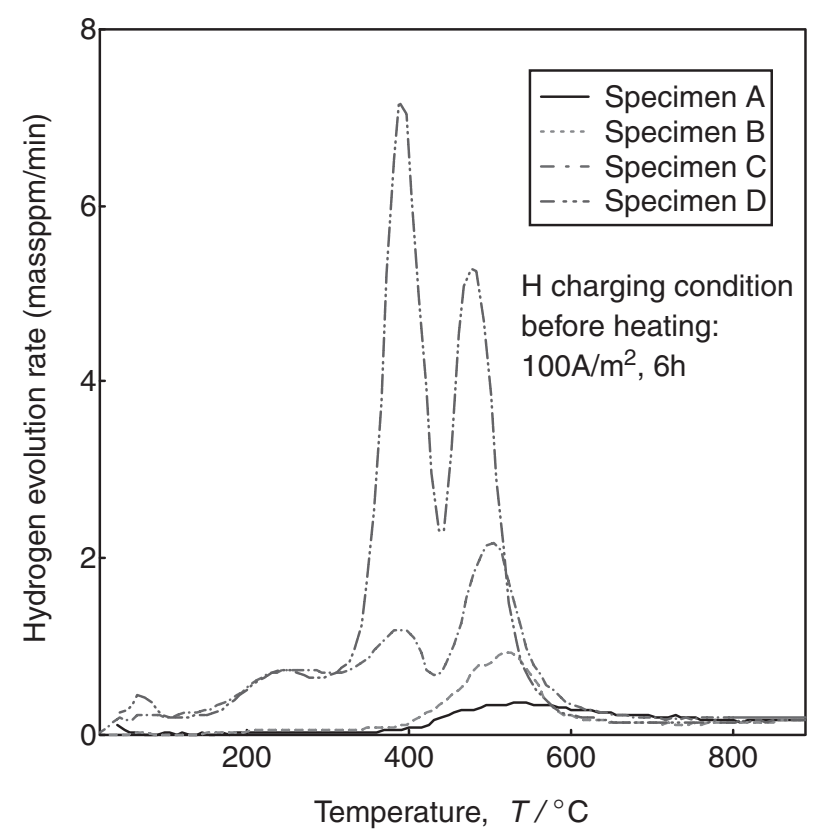

Fig. 5 Hydrogen desorption rate vs. temprature.

hydrogen charging for $6 \mathrm{~h}$. Mainly, four peaks of hydrogen evolution were observed in the hydrogen charged specimens around $100^{\circ} \mathrm{C}, 250^{\circ} \mathrm{C}, 350^{\circ} \mathrm{C}$ and $500^{\circ} \mathrm{C}$. This suggests that different types of hydrogen trapping site exist in the specimen inside. Then, hydrogen concentration was calculated by integrating the relation between hydrogen desorption rate and heating time ranging from room temperature to $900^{\circ} \mathrm{C}$. The hydrogen concentration in Specimen A, B, C, D was 77 massppm, 161 massppm, 308 ppm and 625 massppm, respectively. It is interesting to note that Specimen D contained the highest amount of hydrogen does not show the spontaneous bending. Thus, it is presumed that the difference of hydrogen concentration in the thickness

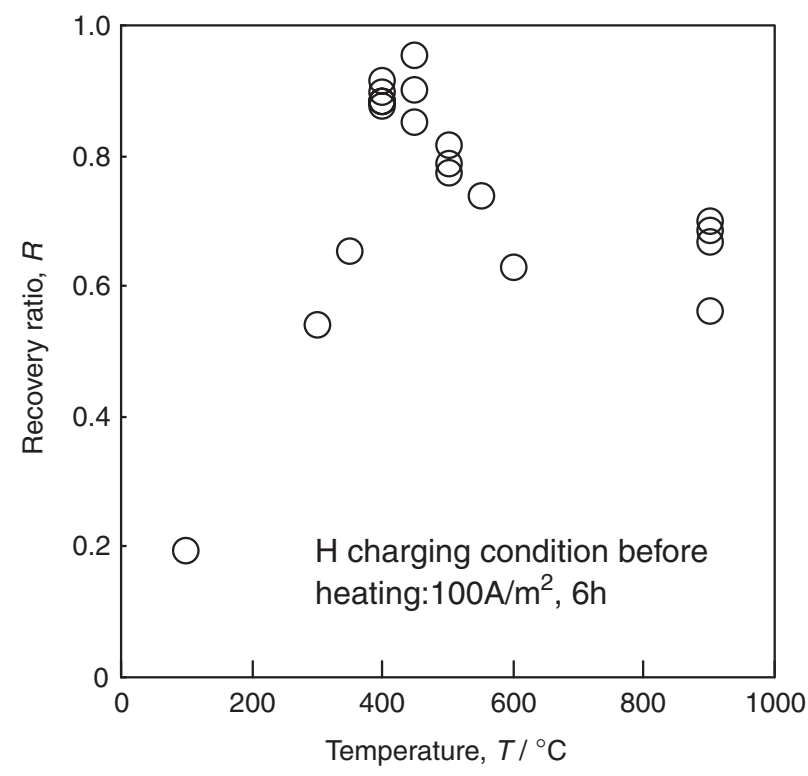

Fig. 6 Recovery ratio vs. heating temperatures of the bent specimens.

direction, not the total hydrogen amount, would be related to the degree of the spontaneous bending. Through a series of TDA experiments, it was also found that the recovery of the spontaneous bending was brought about when the bent specimens were heated in an argon atmosphere. Based on the TDA results, it was considered that the recovery of the spontaneous bending by heating was caused by the hydrogen release from the specimen. Then, the recovery ratio of the spontaneous bending was evaluated by heating the bent specimens to the temperatures corresponding to the peaks of hydrogen evolution as shown before in Fig. 5. The recovery ratio $R$ was defined as follows:

$$
R=\frac{d_{\mathrm{V}}-d_{\mathrm{H}}}{d_{\mathrm{V}}}
$$

Here, $d_{\mathrm{V}}$ is the vertical displacement after hydrogen charging for $6 \mathrm{~h}$ and $d_{\mathrm{H}}$ is the vertical displacement of the bent specimen after heating. The relationship between the recovery ratio and the heating temperature is shown in Fig. 6. It was found that the highest recovery ratio was obtained around $450^{\circ} \mathrm{C}$. This suggests that the hydrogen trapping sites related to the evolution peaks below $450^{\circ} \mathrm{C}$ is closely related to the bending.

\subsection{Effect of oxide film on spontaneous bending}

Effect of oxidation on spontaneous bending was also examined. In order to oxidize the specimen, the bent specimen by hydrogen charging was previously heated to $450^{\circ} \mathrm{C}$ in an air furnace and cooled to room temperature. When the oxidized specimen was again hydrogen charged cathodically without polishing and heated to $450^{\circ} \mathrm{C}$, spontaneous bending was not observed. This indicates that surface oxidized film affects the spontaneous bending, possibly due to preventing the absorption of hydrogen from the atmosphere. In contrast, when one side of the oxidized specimen surfaces was buffed and then hydrogen charged chathodically with a current density of $100 \mathrm{Am}^{-2}$ for $6 \mathrm{~h}$, the spontaneous bending was again identified as shown in Fig. 7. Therefore, it 


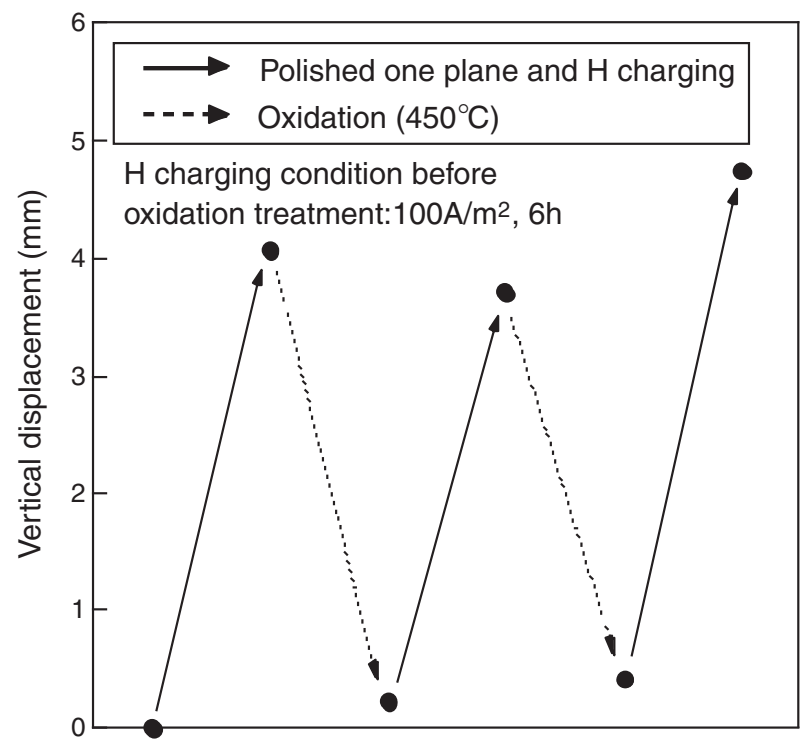

Fig. 7 Reappearance of the spontaneous bending due to the cyclic treatments, buffing plus hydrogen charging and oxidation.

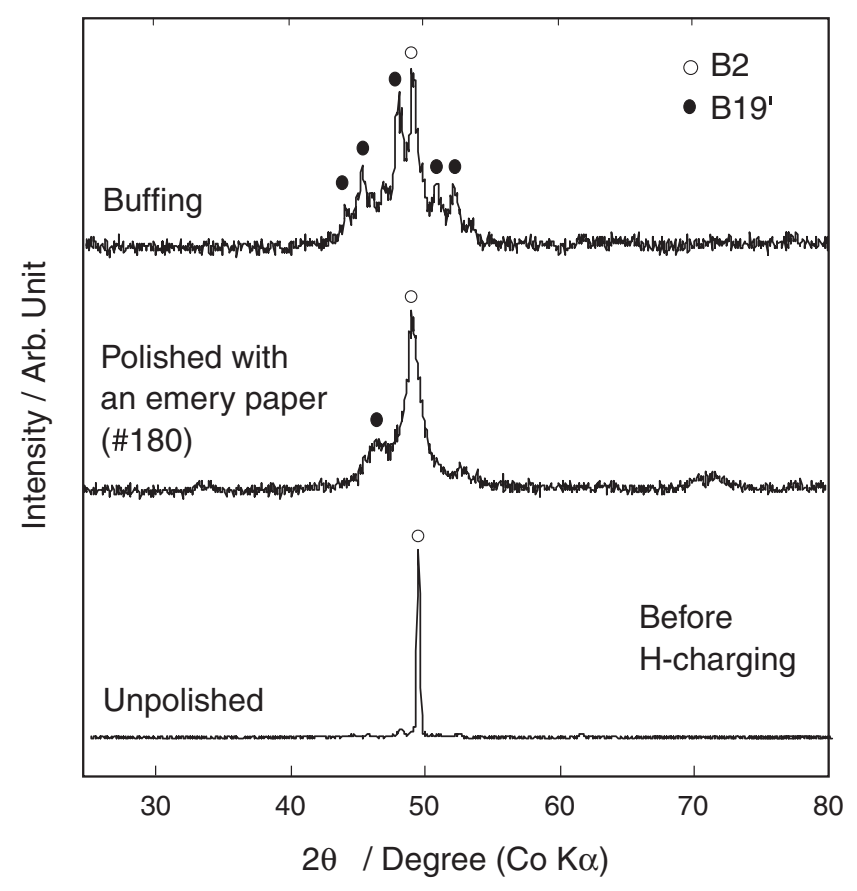

Fig. 8 XRD spectrum in the specimen surfaces before hydrogen charging.

is noted that the spontaneous bending phenomenon can be repeatable even after the oxidation if the oxidized film is fully removed by polishing before hydrogen charging.

\subsection{Structural change of specimen surfaces}

In the previous sections, the relationship among the spontaneous bending, the hydrogen concentration and the surface condition was investigated. Here, XRD analysis was performed to clarify the microstructural changes of the specimen surfaces before and after polishing, hydrogen charging and heating after hydrogen charging. Figure 8 shows the effect of polishing condition on the diffraction angles before hydrogen charging. The main diffraction angle

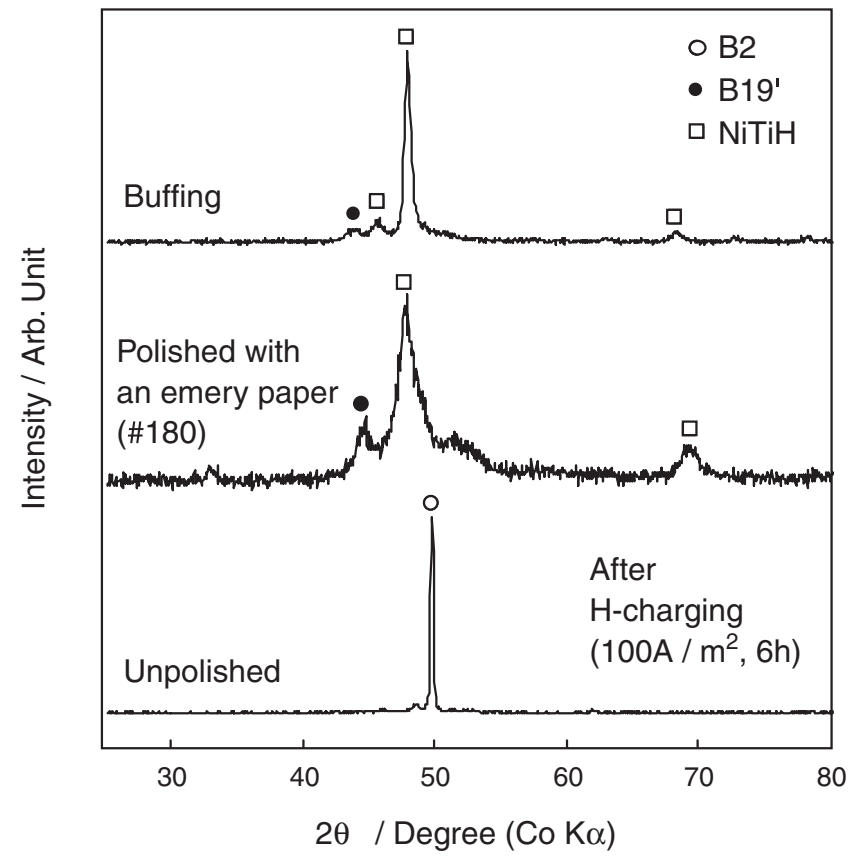

Fig. 9 XRD spectrum in the specimen surfaces after hydrogen charging.

(110) around $50^{\circ}$ corresponding to the B2 structure shifted slightly $\left(0.25^{\circ} \sim 0.3^{\circ}\right)$ to lower angles due to polishing. In addition, the main diffraction angle of the polished specimens was expanded in comparison to the specimen without polishing. This indicated that the crystal lattice was highly distorted in the polished specimens. Moreover, in the polished specimens, the diffraction angles indicating the B19' martensite structure was partly identified. The tendency was more prominent in the buffed specimen. This implies that the internal stress and strain in the limited surface region exceeds the critical stress and strain for the martensite transformation $\left(\sigma=120 \mathrm{MPa}, \varepsilon=3.0 \%^{8)}\right)$ by the polishing. It is reported ${ }^{12)}$ that the strain-induced martinsite phase in the $\mathrm{Ni}$-Ti alloy promotes the hydrogen desorption as compared to the austenite phase. Thus, it is presumed that the hydrogen absorption into the specimen was enhanced by the partial strain-induced martensite transformation as well as the crystal lattice distortions due to the polishing. Figure 9 shows the comparison of the diffraction angles around $50^{\circ}$ in the specimens after hydrogen charging. The formation of $\mathrm{NiTiH}$ hydride phases was clearly identified when the polished specimens were hydrogen charged, while that was not identified in the specimen without polishing. This shows that the phase transformation from $\mathrm{B} 19^{\prime}$ to NiTiH also takes place during hydrogen charging. This agreed well with the reported results showing the formation of $\mathrm{NiTiH}$ hydrides in a buffed 50.9 at\% Ni-Ti alloy after cathodic polarization. ${ }^{13)}$ Figure 10 shows the comparison of the diffraction angles in the buffed and hydrogen charged specimens before and after heating to $450^{\circ} \mathrm{C}$. Due to the recovery of spontaneous bending by heating, the diffraction peaks relating to the $\mathrm{NiTiH}$ phases almost disappeared and that changed similar to the original state just before hydrogen charging as previously shown in Fig. 8. These data support the conclusion that the bending is also correlated with the formation of the $\mathrm{NiTiH}$ phase by hydrogen charging in the limited surface region. 


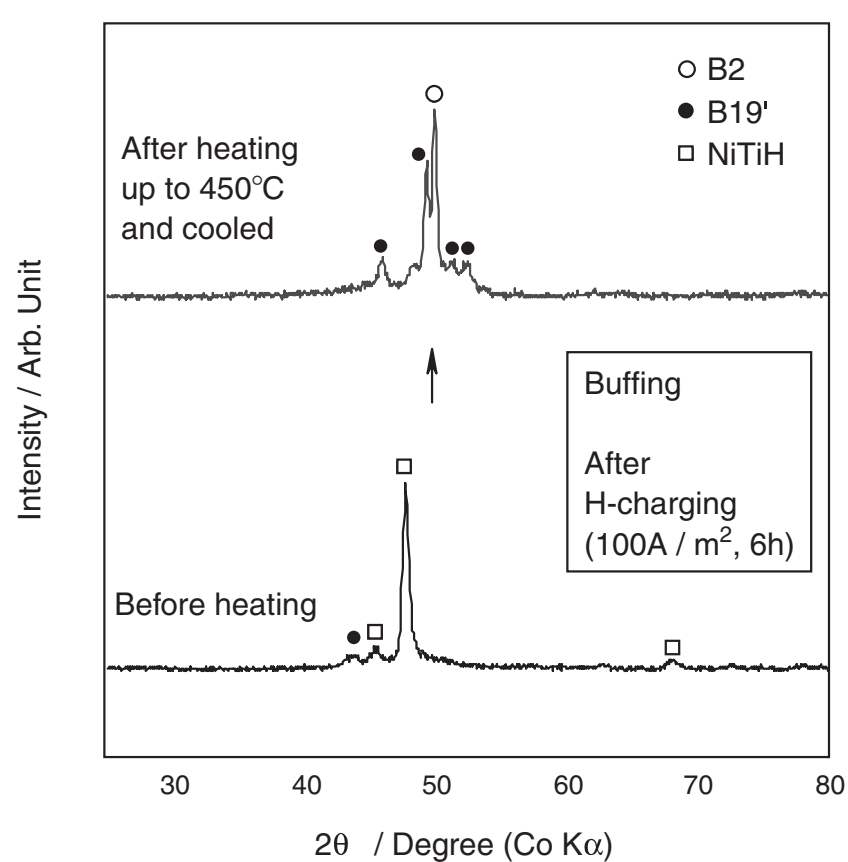

Fig. 10 XRD spectrum in the bent specimens before and after heating to $450^{\circ} \mathrm{C}$.

\section{Summary}

The effect of hydrogen charging on spontaneous bending in the Ni-Ti alloy plate was investigated. The results obtained are summarized as follows: (1) The spontaneous bending was brought about when only one side of the specimen surfaces was polished and then hydrogen charged cathodically. (2) The degree of the spontaneous bending was closely related to the difference of the structural change in both sides of the surfaces and the hydrogen concentration in the thickness direction. (3) The spontaneous bending almost disappeared when the bent specimen by hydrogen charging was heated to the temperature $\left(450^{\circ} \mathrm{C}\right)$ corresponding to the maximum hydrogen evolution peak obtained by TDA. (4) The spontaneous bending was correlated with the phase transformation from $\mathrm{B} 19^{\prime}$ to $\mathrm{NiTiH}$ by hydrogen charging in the limited surface region.

\section{Acknowledgements}

The authors are grateful to Kobe steel Co., Ltd. for providing the Ni-Ti alloy plate. We are also grateful to Dr. H. Ogi and Dr. N. Nakamura for technical support in the XRD experiment.

\section{REFERENCES}

1) T. Honma and H. Takei: J. Japan. Inst. Metals 39 (1975) 175.

2) Y. Adachi, N. Wade and Y. Hosoi: J. Japan. Inst. Metals 54 (1990) 525-531.

3) T. Asaoka, T. Kamimura, H. Saito and Y. Ishida: J. Japan Inst. Metals 56 (1992) 1111-1117.

4) N. Wade, Y. Adachi and Y. Hosoi: Scripta Metallurgica 24 (1990) 1051-1055.

5) T. Asaoka, H. Yamashita, H. Saito and Y. Ishida: J. Japan Inst. Metals 57 (1993) 1123-1129.

6) H. Hagi, M. Mizuno and T. Ibe: J. Surface Sci. Soc. Jpn. 48 (1997) 826-831.

7) K. Yokoyama, S. Watabe, K. Hamada, J. Sakai, K. Asaoka and M. Nagumo: Mater. Sci. Eng. A. 371 (2003) 91-97.

8) K. Horikawa, Y. Kawabata and H. Kobayashi: Proc. 11th World Congress on Titanium, (2007) pp. 19-25.

9) K. Yokoyama, K. Hamada and K. Asaoka: Mater. Trans. 42 (2001) 141-144.

10) K. Yokoyama, T. Eguchi, K. Asaoka and M. Nagumo: Mater. Sci. Eng. A. 374 (2004) 177-183.

11) K. Horikawa, Y. Kawabata and H. Kobayashi: Japanese Patent applied for, (2007) 049187.

12) K. Yokoyama, M. Tomita, K. Asaoka and J. Sakai: Scr. Mater. 57 (2007) 397-396.

13) H. Hagi, M. Mizuno and T. Ibe: J. Surface Sci. Soc. Jpn. 48 (1997) $337-342$. 